\title{
EULAR recommendations for vaccination in adult patients with autoimmune inflammatory rheumatic diseases
}

\author{
S van Assen, ${ }^{1} \mathrm{~N}$ Agmon-Levin, ${ }^{2} 0$ Elkayam, ${ }^{3,4}$ R Cervera, ${ }^{5}$ M F Doran, ${ }^{6}$ \\ M Dougados, ${ }^{7}$ P Emery, ${ }^{8,9}$ P Geborek, ${ }^{10} \mathrm{~J}$ P A loannidis, ${ }^{11-14}$ D R W Jayne, ${ }^{15}$ \\ C G M Kallenberg, ${ }^{16}$ U Müller-Ladner, ${ }^{17}$ Y Shoenfeld ${ }^{2,4} \mathrm{~L}$ Stojanovich, ${ }^{18} \mathrm{G}$ Valesini, ${ }^{19}$ \\ N M Wulffraat, ${ }^{20} \mathrm{M}$ Bij ${ }^{12}$
}

- Additional tables are published online only. To view these files please visit the journal online http://ard.bmj. com

For numbered affiliations see end of article

\section{Correspondence to}

$S$ van Assen, Department of Internal Medicine, Division of Infectious Diseases, University Medical Centre Groningen, AA41 P 0 Box 30 001, 9700 RB Groningen, The Netherlands: s.van.assen@int.umcg.nl

Accepted 4 October 2010 Published Online First 3 December 2010

\section{ABSTRACT}

Objectives To develop evidence-based European League Against Rheumatism (EULAR) recommendations for vaccination in patients with autoimmune inflammatory rheumatic diseases (AllRD).

Methods A EULAR task force was composed of experts representing 11 European countries, consisting of eight rheumatologists, four clinical immunologists, one rheumatologist/clinical immunologist, one infectious disease physician, one nephrologist, one paediatrician/ rheumatologist and one clinical epidemiologist. Key questions were formulated and the eligible spectrum of AllRD, immunosuppressive drugs and vaccines were defined in order to perform a systematic literature review. A search was made of Medline from 1966 to October 2009 as well as abstracts from the EULAR meetings of 2008 and 2009 and the American College of Rheumatology (ACR) meetings of 2007 and 2008. Evidence was graded in categories I-IV, the strength of recommendations was graded in categories A-D and Delphi voting was applied to determine the level of agreement between the experts of the task force. Results Eight key questions and 13 recommendations addressing vaccination in patients with AllRD were formulated. The strength of each recommendation was determined. Delphi voting revealed a very high level of agreement with the recommendations among the experts of the task force. Finally, a research agenda was proposed. Conclusion Recommendations for vaccination in patients with AIIRD based on the currently available evidence and expert opinion were formulated. More research is needed, particularly regarding the incidence of vaccine-preventable infectious diseases and the safety of vaccination in patients with AlIRD.

Patients with autoimmune inflammatory rheumatic diseases (AIIRD) are at increased risk of contracting infections. ${ }^{1-10}$ The increased susceptibility to infection can be attributed to by any of the following: the immunosuppressive effect of the underlying AIIRD, the occurrence of a 'locus minoris resistentiae' as a sequel of the AIIRD and the use of immunomodulatory medication to treat the AIIRD. The possible contribution of biological agents to the risk of infection is of particular interest, especially since increasingly more indications are being recognised for their use, they are increasingly being used earlier in the course of AIIRD and newer agents are becoming available. ${ }^{11-23}$
Vaccination is an attractive method to prevent certain infections. The efficacy of vaccinations in patients with AIIRD, however, may be reduced and there is a potential risk of flares of the underlying AIIRD following vaccination.

Our aim was to develop recommendations for vaccination in patients with AIIRD in line with the standard operating procedures of the European League Against Rheumatism (EULAR), combining evidence from clinical studies with expert opinion when sufficient evidence was lacking. Our recommendations target all physicians and nurses who are involved in the care for patients with AIIRD.

\section{METHODS \\ Expert Committee}

The committee consisted of eight rheumatologists (OE, MFD, MD, PE, PG, UML, LS, GV), four clinical immunologists (NAL, RC, CGMK, YS), one rheumatologist/clinical immunologist $(\mathrm{MB})$, one infectious disease physician (SvA), one nephrologist (DRWJ), one paediatrician/rheumatologist (NMW) and one clinical epidemiologist (JPAI), representing 11 European countries.

\section{Definitions}

In these recommendations, the term 'efficacy' represents the capability of a vaccine to mount a protective immune response because vaccination studies in patients with AIIRD addressing clinical end points are scarce. Moreover, it should be acknowledged that in vitro immune responses may not always correlate well with clinical effectiveness. This should be taken into account when interpreting the available evidence for these recommendations.

\section{Development of recommendations}

The experts were invited to define the AIIRD, the vaccines and the immunosuppressive medications which were to be used as search terms for the systematic literature review. Furthermore, key questions regarding vaccination of patients with AIIRD were formulated.

Medline (via PubMed) was searched from 1966 to October 2009 as well as the abstracts from the meetings of EULAR 2008 and 2009 and of the American College of Rheumatology (ACR) 2007 and 2008. As search terms, the MESH terms for the defined AIIRD, immunosuppressive medications 
and vaccines were combined. Only articles in English and concerning patients aged $>16$ years were included. Other papers that were considered relevant in the opinion of the experts could be added. The results of the systematic literature review (performed by SvA, MB, NAL, OE) were sent to the committee before the second meeting together with proposals for recommendations.

Thirteen recommendations were formulated. For each recommendation we used a widely-accepted hierarchy for categorising the available evidence and the strength of the recommendations (see table 1 in the online supplement). A Delphi exercise with closed voting followed. During this exercise the 13 recommendations were separately voted on and given a score from 0 (absolutely no agreement with the proposed recommendation) to 10 (maximal possible support for the recommendation). The means and SDs of the scores of the whole group were calculated to determine the level of agreement among the experts for each recommendation. Finally, a research agenda was created.

\section{RESULTS}

Twenty-seven eligible AIIRD, 17 immunosuppressive medications and 29 vaccines (table 1) were identified and eight key questions (box 1) were composed for the systematic literature review. The task force members agreed on 13 recommendations, reaching a high level of agreement according to the Delphi scores (table 2).

\section{Recommendations}

Each recommendation is followed in parenthesis with the grade of the evidence, the strength of the recommendation and the Delphi voting score.
(1) The vaccination status should be assessed in the initial work-up of patients with AIIRD (no grade of evidence possible; strength of recommendation D; Delphi vote 9.50)

In order to make recommendations for the individual patient with AIIRD, it is necessary to know which vaccines the patient received in the past according to box 2 . Catch-up vaccination might be considered for missed vaccinations that are recommended for the general population. Also, adverse events and flares of the underlying AIIRD following former vaccinations should be queried since these might be (relative) contraindications for certain future vaccinations.

(2) Vaccination in patients with AllRD should ideally be administered during stable disease (no grade of evidence possible; strength of recommendation D; Delphi vote 8.88)

No studies have been performed comparing efficacy and harms between patients with AIIRD with stable and unstable disease. Moreover, almost all vaccination studies in patients with AIIRD addressed patients with quiescent disease. Studies that also included patients with moderate or severe disease activity did not show more frequent side effects or disease flares, or decreased efficacy in patients with AIIRD compared with healthy controls. ${ }^{24-26}$ However, the numbers of patients in these studies were too small to conclude that vaccination during active disease is safe and efficacious. Therefore, based on theoretical risks of disease flare following vaccination in unstable patients with AIIRD, vaccination is preferentially administered during stable disease, according to expert opinion.

Table 1 AllRD, immunomodulating agents and vaccines considered in the literature search and recommendations

\begin{tabular}{|c|c|c|}
\hline AlIRD & Immunomodulating agents & Vaccines \\
\hline Rheumatoid arthritis & Corticosteroids & BCG \\
\hline Serum lupus erythematosus & Methotrexate & Cholera \\
\hline Antiphospholipid syndrome & Sulfasalazine & Diphtheria \\
\hline Adult Still disease & Leflunomide & Hepatitis A \\
\hline Systemic sclerosis & Hydroxychloroquine & Hepatitis B \\
\hline Sjögren syndrome & Azathioprine & Haemophilus influenzae b \\
\hline Mixed connective tissue disease & Mycophenolic acid preparations & Human papillomavirus \\
\hline Relapsing polychondritis & Ciclosporine & Influenza \\
\hline Giant cell arteritis & Tacrolimus & Japanese encephalitis \\
\hline Polymyalgia rheumatica & Cyclophosphamide & Measles* \\
\hline Takayasu arteritis & Biologicals: & Mumps* \\
\hline Polyarteritis nodosa & TNF $\alpha$ blocking agents & Neisseria meningitidis (A/C/Y/W135, C conjugated) \\
\hline ANCA-associated vasculitis & Infliximab & Pertussis \\
\hline Microscopic polyangiitis & Etanercept & Poliomyelitis (parenteral and oral*) \\
\hline Wegener granulomatosis & Adalimumab & Rabies \\
\hline Churg-Strauss syndrome & Rituximab & Rubella* \\
\hline Behçet disease & Tocilizumab & $\begin{array}{l}\text { Streptococcus pneumoniae (polysaccharide and } \\
\text { conjugated) }\end{array}$ \\
\hline Goodpasture disease & Abatacept & Tetanus toxoid \\
\hline Cryoglobulinaemic syndrome & Anakinra & Tick-borne encephalitis \\
\hline Polymyositis & & Typhoid fever (parenteral and oral*) \\
\hline Dermatomyositis & & Varicella zoster* \\
\hline Clinically amyopathic dermatomyositis & & Yellow fever* \\
\hline \multicolumn{3}{|l|}{ Sporadic inclusion body myositis } \\
\hline \multicolumn{3}{|l|}{ Antisynthetase syndrome } \\
\hline \multicolumn{3}{|l|}{ Eosinophilic myositis } \\
\hline \multicolumn{3}{|l|}{ Eosinophilic fasciitis } \\
\hline \multicolumn{3}{|l|}{ Spondylathropathies } \\
\hline Periodic fever syndromes & & \\
\hline
\end{tabular}


(3) Live attenuated vaccines should be avoided whenever possible in immunosuppressed patients with AIIRD (grade of evidence IV; strength of recommendation D; Delphi vote 9.25)

Live attenuated vaccines (table 1) might lead to (severe) infections in immunosuppressed patients. It is not known what level

\section{Box 1 Key questions}

1. Is the risk of infections for which vaccines are available increased in patients with autoimmune inflammatory rheumatic diseases (AIIRD) in general, and specifically in those with active disease and in those using immunomodulating agents?

2. Do vaccines decrease the risk of infections in patients with AlIRD in general, and specifically in those with unstable disease and in those using immunomodulating agents?

3. Do vaccines cause any significant harm in patients with AlIRD in general, and specifically in those with unstable disease and in those using immunomodulating agents?

4. Does the timing of vaccination in relation to disease activity and receipt of immunomodulating agents affect the effectiveness of vaccination in patients with AlIRD?

5. Does the timing of vaccination in relation to disease activity and receipt of immunomodulating agents affect important harms of vaccination in patients with AIIRD?

6. Does revaccination with any vaccines increase the effectiveness in patients with AIRD?

7. Does revaccination with any vaccine increase significant harms in patients with AIRD?

8. Is vaccination in patients with AIIRD cost-effective? of immunosuppression renders patients to be at risk for infections caused by these vaccines, and this risk should be balanced to the risk of (severe) infection the vaccine aims to prevent.

Measles, mumps and rubella (MMR) vaccine has been administered without subsequent infection to paediatric patients 2 years after bone marrow transplantation ${ }^{27}$ and varicella vaccine has been administered without subsequent infection in HIV-infected children with a CD4 percentage $\geq 15 \%$ or a CD4 count $\geq 200 / \mathrm{mm}^{3}{ }^{28}$ Studies are ongoing for herpes zoster vaccine in adult patients with HIV with a CD4 count $\geq 200 / \mathrm{mm}^{3}$ (http://www.clinicaltrials.gov/ct2/show/NCT00851786?term =zostavax+hiv\&rank=1) and in older patients on treatment with prednisone 5-20 mg/day (http://www.clinicaltrials.gov/ ct2/show/NCT00546819?term=zostavax+corticosteroid\&ra $\mathrm{nk}=1$ ). The Advisory Committee on Immunization Practices (ACIP) stated that herpes zoster vaccine may be administered to patients when treated with short-term corticosteroid therapy (<14 days); low to moderate doses of corticosteroids ( $<20 \mathrm{mg}$ / day of prednisone or equivalent); intra-articular, bursal or tendon corticosteroids injections; long-term alternate-day treatment with low to moderate doses of short-acting systemic corticosteroids; therapy with methotrexate (MTX; $<0.4 \mathrm{mg} / \mathrm{kg} /$ week), azathioprine ( $<3.0 \mathrm{mg} / \mathrm{kg} /$ day) or 6 -mercaptopurine $(<1.5 \mathrm{mg} /$ $\mathrm{kg} /$ day). ${ }^{29}$ It must be emphasised that these recommendations are based on expert opinion only and require further investigation. The EULAR task force on vaccination recommends avoiding the use of live attenuated vaccines in immunosuppressed patients with AIIRD whenever possible. MMR, varicella and herpes zoster vaccine might be exceptions to this rule and may be considered in mildly immunosuppressed patients with AIIRD on a case-by-case basis. Temporary discontinuation of immunosuppressive medication before vaccination with live attenuated

Table 2 Recommendations for vaccination in adult patients with autoimmune inflammatory rheumatic diseases with level of evidence, strength of recommendations and results of Dephi voting per recommendation

\begin{tabular}{|c|c|c|c|c|c|}
\hline \multirow[b]{2}{*}{ Recommendation } & \multicolumn{3}{|l|}{ Category of evidence } & \multirow{2}{*}{$\begin{array}{l}\text { Strength of } \\
\text { recommendation }\end{array}$} & \multirow{2}{*}{$\begin{array}{l}\text { Mean (SD) level } \\
\text { of agreement } \\
\text { by Delphi voting } \\
\text { (VAS) }\end{array}$} \\
\hline & $\begin{array}{l}\text { Increased incidence } \\
\text { of VP infection }\end{array}$ & $\begin{array}{l}\text { Efficacy of } \\
\text { vaccination }\end{array}$ & $\begin{array}{l}\text { Harms of } \\
\text { vaccination }\end{array}$ & & \\
\hline $\begin{array}{l}\text { The vaccination status should be assessed in the initial investigation of patients with } \\
\text { AllRD }\end{array}$ & - & & & $\mathrm{D}$ & $9.50(0.97)$ \\
\hline $\begin{array}{l}\text { Vaccination in patients with AlIRD should ideally be administered during stable } \\
\text { disease }\end{array}$ & - & & & $\mathrm{D}$ & $8.88(1.26)$ \\
\hline $\begin{array}{l}\text { Live attenuated vaccines should be avoided whenever possible in } \\
\text { immunosuppressed patients with AllRD }\end{array}$ & IV & & & $\mathrm{D}$ & $9.25(1.13)$ \\
\hline $\begin{array}{l}\text { Vaccination in patients with AllRD can be administered during the use of DMARDs } \\
\text { and TNF } \alpha \text { blocking agents, but should ideally be administered before starting B cell- } \\
\text { depleting biological therapy }\end{array}$ & II & & & B & $9.13(1.02)$ \\
\hline Influenza vaccination should be strongly considered for patients with AIIRD & III & $\mathrm{lb}$ & $\mathrm{lb}$ & $\mathrm{B}-\mathrm{C}$ & $9.00(1.10)$ \\
\hline $\begin{array}{l}\text { 23-valent polysaccharide pneumococcal vaccination should be strongly considered } \\
\text { for patients with AlIRD }\end{array}$ & III & $\mathrm{lb}$ & $\mathrm{lb}$ & $\mathrm{B}-\mathrm{C}$ & $8.19(1.38)$ \\
\hline $\begin{array}{l}\text { Patients with AIIRD should receive tetanus toxoid vaccination in accordance with } \\
\text { recommendations for the general population. In case of major and/or contaminated } \\
\text { wounds in patients who received rituximab within the last } 24 \text { weeks, passive } \\
\text { immunisation with tetanus immunoglobulin should be administered }\end{array}$ & - & II & II & $\mathrm{B}-\mathrm{D}$ & $9.19(1.11)$ \\
\hline Herpes zoster vaccination may be considered in patients with AIIRD & III & - & IV & C-D & $8.00(1.59)$ \\
\hline HPV vaccination should be considered in selected patients with AIIRD & III & - & - & C-D & $8.44(1.41)$ \\
\hline $\begin{array}{l}\text { In hyposplenic/asplenic patients with AIIRD, influenza, pneumococcal, Haemophilus } \\
\text { influenzae b and meningococcal C vaccinations are recommended }\end{array}$ & IV & & & $\mathrm{D}$ & $9.50(0.82)$ \\
\hline Hepatitis A and/or B vaccination is only recommended in patients with AllRD at risk & - & $\|^{*}$ & $I I I^{*}$ & $\mathrm{D}$ & $9.13(0.89)$ \\
\hline $\begin{array}{l}\text { Patients with AlIRD who plan to travel are recommended to receive their } \\
\text { vaccinations according to general rules, except for live attenuated vaccines which } \\
\text { should be avoided whenever possible in immunosuppressed patients with AllRD }\end{array}$ & - & & & $D$ & $9.25(1.24)$ \\
\hline BCG vaccination is not recommended in patients with AlIRD & III & - & - & $\mathrm{D}$ & $9.38(1.09)$ \\
\hline
\end{tabular}

${ }^{*}$ For hepatitis B only

AllRD, autoimmune inflammatory disease; BCG, Bacillus Calmette-Guérin; DMARD, disease-modifying antirheumatic drug; HPV, human papillomavirus; TNF, tumour necrosis factor VAS, visual analogue scale; VP, vaccine-preventable. 
Box 2 Vaccinations to be checked during the initial investigation (by history taking)

Haemophilus influenzae b
Hepatitis A
Hepatitis B
Human papillomavirus
Influenza
Neisseria meningitides
Rubella (for women of childbearing age)
Streptococcus pneumoniae
Tetanus toxoid

vaccines might also be considered, but there are no studies to support this strategy.

(4) Vaccination in patients with AlIRD can be administered during the use of disease-modifying antirheumatic drugs and tumour necrosis factor $\alpha$ blocking agents but should ideally be administered before starting $B$ cell depleting biological therapy (grade of evidence lla; strength of recommendation B; Delphi vote 9.13)

The efficacy of vaccination during the use of disease-modifying antirheumatic drugs (DMARDs), glucocorticoids and/ or tumour necrosis factor (TNF) $\alpha$ blocking agents has been studied in patients with rheumatoid arthritis (RA), systemic lupus erythematosus (SLE), ANCA-associated vasculitis (AAV) and systemic sclerosis (SSc). Influenza, pneumococcal, hepatitis $B$, tetanus toxoid and Haemophilus influenzae b vaccination were addressed. Most controlled studies showed responses in patients with AIIRD following vaccination comparable to those in healthy controls, ${ }^{24} 25$ 30-62 while some showed slightly reduced efficacy. ${ }^{38} 4345474961$ 63-67 Of note, azathioprine hampered the response following influenza vaccination in patients with SLE but the majority of patients still develop protective levels of antibodies. ${ }^{63} 68$ The combination of TNF $\alpha$ blocking agents and MTX reduced the response to pneumococcal vaccination in patients with RA. 456769 Finally, humoral responses following influenza vaccination 1-3 months after treatment with rituximab 417078 as well as humoral responses following pneumococcal vaccination 28 weeks after treatment with ritux$i m a b^{71}$ are severely hampered. Tetanus toxoid vaccination led to adequate immune responses 24 weeks after rituximab administration. ${ }^{71}$ Vaccines should ideally be administered before B celldepleting biological therapy is started or, when patients are on such a treatment already, at least 6 months after the start but 4 weeks before the next course.

(5) Inactivated influenza vaccination should be strongly considered for patients with AIIRD (grade of evidence Ib-III; strength of recommendation $\mathrm{B}-\mathrm{C}$; Delphi vote 9.00 )

Although the exact incidence of influenza is unknown in patients with AIIRD, their risk of dying from pulmonary infections is increased. ${ }^{4} 52$ Influenza vaccination has been shown to reduce admissions for and mortality from influenza/pneumonia in elderly people with rheumatological diseases or vasculitis ${ }^{7374}$ and is efficacious in patients with RA, SLE, AAV and SSc, even when treated with DMARDs, infliximab, etanercept or adalimumab, ${ }^{24-26} 30-41$ 47-50 636768 75-77 but with rituximab as an exception. ${ }^{41} 7078$ Adverse events of influenza vaccination in patients with AIIRD seem comparable to those in healthy controls, although there are no studies that are sufficiently powered with regard to safety. This recommendation regards seasonal influenza vaccination as well as pandemic swine flu vaccination, although no studies have been performed on efficacy and safety of swine flu vaccination in patients with AIIRD. Because some of the swine flu vaccines contain the adjuvant MF-59, an oil-inwater emulsion that potentiates the humoral response, it is reassuring that a large meta-analysis showed no difference in the occurrence of adverse events that were of autoimmune origin between persons vaccinated with influenza vaccine with and without MF-59. ${ }^{79}$

\section{(6) 23-valent polysaccharide pneumococcal vaccination (23-PPV)} should be strongly considered for patients with AIIRD (grade of evidence Ib-III; strength of recommendation B-C; Delphi vote 8.19) As stated above, patients with AIIRD are at increased risk of dying from pulmonary infections compared with the general population, ${ }^{2} 4572$ with pneumococci being considered as one of the main causative pathogens. Pneumococcal vaccination induces an adequate to slightly reduced humoral response in patients with RA, SLE, psoriatic arthritis, ankylosing spondylitis and SSc, even when treated with immunosuppressive drugs. ${ }^{36} 42-454751-54627180$ MTX, with or without TNF $\alpha$ blocking agents ${ }^{45} 69$ and, in particular, rituximab ${ }^{71}$ reduces the humoral response following pneumococcal vaccination. It is unknown if and when revaccination should take place and if the new conjugated pneumococcal vaccines, whether or not in combination with 23-PPV (so-called prime-and-boost strategy), induce more and/or more durable immunity to pneumococci in patients with AIIRD. Pneumococcal vaccination seems safe in patients with AIIRD, but again the available studies were not adequately powered for analysing safety.

(7) Patients with AllRD should receive tetanus toxoid vaccination in accordance to recommendations for the general population. In case of major and/or contaminated wounds in patients who received rituximab within the last 24 weeks, passive immunisation with tetanus immunoglobulins should be administered (grade of evidence II; strength of recommendation B-D; Delphi vote 9.19)

In patients with RA and SLE, efficacy for tetanus toxoid vaccination has been demonstrated to be comparable with healthy controls. ${ }^{30465859}$ This also holds true for patients with RA on immunosuppressive drugs, including those who have been treated with rituximab 24 weeks earlier. ${ }^{71}$ However, since no data are available regarding the efficacy of tetanus toxoid vaccine within 24 weeks after treatment with rituximab, ${ }^{71}$ we recommend that patients with AIIRD who are treated with rituximab less than 24 weeks earlier be passively immunised with tetanus immunoglobulins in case of a serious risk of contracting tetanus (ie, in case of major and/or contaminated wounds).

(8) Herpes zoster vaccination may be considered in patients with AlIRD (grade of evidence III-IV; strength of recommendation C-D; Delphi vote 8.00)

Compared with the general population, patients with RA, SLE, $\mathrm{AAV}$ and polymyositis/dermatomyositis (PM/DM) have an increased risk of developing herpes zoster. ${ }^{81-99} \mathrm{RA}$ is in itself a risk factor, and the risk of developing herpes zoster is further increased in patients with AIIRD treated with corticosteroids, TNF $\alpha$ blocking agents and non-biological DMARDs, particularly cyclophosphamide, azathioprine and leflunomide $82-85909198$ but not MTX. ${ }^{100}$ One study found an increased risk of herpes zoster in patients with SLE when treated with rituximab. ${ }^{101}$ Lupus disease activity is not a risk factor for herpes zoster. ${ }^{88}$ Herpes zoster vaccine has been shown to reduce herpes zoster and post-herpetic neuralgia in patients over 60 years, ${ }^{102}$ but no studies have been performed in patients with AIIRD. Because of the high burden of herpes zoster in patients with AIIRD, 
herpes zoster vaccination may be considered in these patients, but only when less severely immunosuppressed. The ACIP suggested criteria for immunosuppressed patients who can receive herpes zoster vaccine; however, it must be emphasised that these recommendations are not validated but are based on expert opinion and require further investigation. ${ }^{29}$ It seems prudent to administer herpes zoster vaccine only to patients with AIIRD who are seropositive for varicella zoster antibodies in order to prevent primary varicella infection with the vaccine strain.

(9) Human papillomavirus vaccination should be considered in selected patients with AIIRD (grade of evidence III; strength of recommendation $\mathrm{C}-\mathrm{D}$; Delphi vote 8.44 )

It has been shown that human papillomavirus (HPV) infection occurs more often in patients with SLE, also with the high-risk (oncogenic) subtypes of the virus. ${ }^{103-105}$ A lower percentage of these infections $(31.8 \%)$ is spontaneously cleared by patients with SLE, ${ }^{106}$ leading to an increased risk of developing cervical cancer. The risk factors for contracting HPV infection are the same in patients with SLE as in the general population. ${ }^{103} 105$ The efficacy of HPV vaccination has not been investigated in patients with AIIRD. HPV vaccination is recommended for young women in many countries and should be considered for women with SLE until the age of 25 years. The quadrivalent (q) HPV vaccine has been associated with venous thromboembolic events (VTE). However, of the 31 cases $(0.2 / 100.000$ doses of $\mathrm{qHPV}$ vaccine) with objectified VTE, $90 \%$ had a known risk factor for VTE (antiphospholipid syndrome in two cases). ${ }^{107}$

(10) In hyposplenic/asplenic patients with AlIRD influenza, pneumococcal, Haemophilus influenzae b and meningococcal $\mathrm{C}$ vaccinations are recommended (grade of evidence IV; strength of recommendation D; Delphi vote 9.50)

Hyposplenic/asplenic patients are at risk of contracting a socalled 'overwhelming post-splenectomy infection (OPSI)'. OPSI is caused by encapsulated bacteria (eg, Streptococcus pneumoniae, $H$ influenzae b, Neisseria meningitidis) and the mortality of OPSI is up to $70 \% .^{108-112}$ OPSI can occur as a secondary infection after infection with influenza. No studies have addressed the efficacy of vaccination to prevent OPSI in patients who are hyposplenic/ asplenic, but the general consensus is to vaccinate these patients against influenza, $S$ pneumoniae, $H$ influenzae $b$ and $N$ meningitides C. ${ }^{113}$ When hyposplenic/asplenic patients with AIIRD plan to travel to or live in areas where other meningococcal strains are endemic (A, Y, W135), vaccination for these meningococcal subtypes is also indicated. ${ }^{114}$ Prophylactic or on-demand antibiotics and preventive measures for malaria and babesiosis are beyond the scope of these recommendations.

(11) Hepatitis A and/or B vaccination is only recommended in patients with AIIRD at risk (grade of evidence II-III; strength of recommendation B-D; Delphi vote 9.13)

Data on the incidence of hepatitis $A$ and $B$ infection in patients with AIIRD are lacking. Reactivation of hepatitis B infection in patients with AIIRD has been described following treatment with immunosuppressive medication or immediately after discontinuing immunosuppressive medication (including TNF $\alpha$ blocking agents). However, no comparative studies have been published so it is impossible to distinguish whether the immunosuppressive treatment, the disease activity of the AIIRD or the natural course of chronic hepatitis B infection was the cause of the hepatitis flare. Hepatitis $B$ vaccination is efficacious in most patients with AIIRD. ${ }^{55-57}$ Vaccination for hepatitis $\mathrm{A}$ and/or $\mathrm{B}$ is only recommended when the risk of contracting these infections is increased (travel to or residence in endemic countries for hepatitis A and/or B); increased risk of exposure or proven exposure to hepatitis A and/or B (eg, because of medical profession, infected family member or contacts), only when protective antibodies against hepatitis $\mathrm{A}$ and/or B are absent.

(12) Patients with AllRD who plan to travel are recommended to receive their vaccinations according to general rules, except for live attenuated vaccines which should be avoided whenever possible in immunosuppressed patients with AllRD (no grade of evidence; strength of recommendation D; Delphi vote 9.25)

It is unknown whether patients with AIIRD have an increased risk of contracting travel-related vaccine-preventable infections (VPI). In patients with RA and SLE, the risk of tuberculosis (TB) is increased (also see recommendation 13). ${ }^{115-129}$ However, the majority of these TB cases represent reactivations from earlier contracted latent TB infection and Bacillus Calmette-Guérin (BCG) vaccination has not been clearly shown to prevent TB in adults. Influenza is endemic in subtropical and tropical climates during the entire year and is the most frequent VPI among travellers to subtropical and tropical countries. ${ }^{130} 131$ The incidence of influenza in patients with AIIRD is not known. Also the incidence of cholera, diphtheria, hepatitis A, meningococcal infection, poliomyelitis, rabies, tetanus, tick-borne encephalitis, typhoid fever and yellow fever is unknown. Studies addressing the efficacy of influenza vaccination (in patients with RA, SLE, SSc and AAV) ${ }^{24-2630-41 ~ 47-5063676875-77 ~ a n d ~ t e t a n u s ~ t o x o i d ~ v a c c i-~}$ nation (in patients with RA and SLE) 30465859 generally showed responses comparable to those in healthy controls. To protect patients with AIIRD from contracting travel-related VPI, they should receive the vaccinations that are recommended to the general population. Exceptions are vaccinations with BCG vaccine, oral poliomyelitis vaccine, oral typhoid fever vaccine and yellow fever vaccine which contain live attenuated microorganisms and therefore might lead to life-threatening infection in immunosuppressed patients with AIIRD.

(13) BCG vaccination is not recommended in patients with AlIRD (grade of evidence III; strength of recommendation C-D;

Delphi vote 9.38)

The incidence of TB is increased in patients with AIIRD, in particular when treated with immunosuppressive drugs (DMARDs, corticosteroids), ${ }^{115-119}$ 121-124 127-129 especially TNF $\alpha$ blocking agents. ${ }^{116-119} 122$ 127-129 The large majority of these cases of active TB are reactivations of earlier contracted latent TB infections which cannot be prevented by vaccination. Moreover, BCG vaccination has not been clearly demonstrated to be efficacious in preventing TB in adults. Finally, BCG vaccine contains attenuated mycobacteria and vaccination with BCG vaccine has been shown to induce BCG-itis in immunosuppressed patients. ${ }^{132-134}$

\section{Research agenda}

The EULAR Task Force for vaccination in patients with AIIRD agreed on the research agenda as shown in table 2 in the online supplement.

\section{DISCUSSION}

The recommendations for vaccination in patients with AIIRD, as presented above, are based on the current evidence resulting from the systematic literature review and the opinion of selected experts in the fields of rheumatology, clinical immunology, nephrology, paediatric rheumatology/ 
immunology and infectious diseases from 11 European countries. Unfortunately, no randomised controlled studies were available that addressed the efficacy of vaccination in patients with AIIRD on clinical end points. The highest strength of these recommendations is therefore $B$ (see table 1 in online supplement). We did not systematically review the literature on vaccines in the general population without AIIRD, but the experts did take into account their knowledge of this wider literature in formulating the recommendations. In general, it should be noted that, even for the general population, conceptions about the efficiency and efficacy of vaccination have varied over time. There is strong evidence that adequate immune responses are achieved with vaccines, especially for influenza and pneumococcal vaccines, but this may not always translate into equally high efficiency at the clinical protection level. ${ }^{135-137}$

Other infection-preventive measures than vaccination are not addressed in these recommendations, and we suggest a new EULAR task force should be set up to recommend on important issues such as general hygienic measures and antibiotic prophylaxis for patients with AIIRD to further reduce infection-related morbidity and mortality in patients with AIIRD.

Our literature search focused essentially on three important aspects of vaccination in patients with AIIRD: the incidence of infectious diseases for which vaccines are available; the efficacy of vaccinations that are indicated; and the harms of vaccination. We should acknowledge that the grading of the available evidence can differ between the three aforementioned aspects: often little evidence is available for the incidence of VPI and most studies are underpowered with regard to adverse events, while efficacy is best studied for most vaccines. The results of the Delphi voting to the traditional level of evidence are therefore of particular importance since they represent the overall interpretation of the evidence on all aforementioned aspects of vaccination in patients with AIIRD by the panel of experts.

The morbidity and mortality for most VPI increase in patients who are more severely immunosuppressed-for example, when treated with a more intensive immunosuppressive regimen. We therefore stress that the recommendations regarding vaccination in patients with AIIRD should be followed more stringently for more immunosuppressed patients. However, because efficacy can be reduced by immunosuppressive treatment, offering vaccination before starting (intensive) immunosuppressive treatment, in particular rituximab, is advisable.

A note of caution is warranted with regard to the safety of vaccination in patients with AIIRD. Although many case reports have been published demonstrating flares of AIIRD or new-onset autoimmune diseases following vaccination, these adverse events remain rare and a causal relationship has not been proved. Moreover, several controlled studies show no difference in the occurrence of flares of AIIRD after vaccination, although these studies have not been powered to address specific adverse events, but efficacy. Because of the lack of sufficiently powered studies focusing on harms, these issues remain an important item on the research agenda.

Finally, different vaccination schemes have been developed and proposed in different European countries. The exact implementation of the current recommendations may need to take into account local differences in specific countries and settings. Moreover, the recommendations need to be updated on a regular basis (every 3 years), since new evidence will become available with regard to current and new vaccines and current and new immunomodulating treatments.
Author affiliations ${ }^{1}$ Department of Internal Medicine, Division of Infectious Diseases, University Medical Centre Groningen, Groningen, The Netherlands ${ }^{2}$ The Zabludowicz Centre for Auto-immune Diseases, Sheba Medical Center, Tel Hashomer, Israel

${ }^{3}$ Department of Internal Medicine F, Department of Rheumatology, Tel Aviv Medical Center, Tel Aviv, Israel

${ }^{4}$ The "Sackler" Faculty of Medicine, Tel Aviv University, Israel

5Department of Auto-immune Diseases, Hospital Clínic, Barcelona, Spain

${ }^{6}$ Department of Rheumatology, St. James's Hospital, Dublin, Ireland

${ }^{7}$ Department of Rheumatology, Hospital Cochin, Paris, France

${ }^{8}$ Section of Musculoskeletal Disease, Leeds Institute of Molecular Medicine, University of Leeds, Leeds, UK

${ }^{9}$ Musculoskeletal Biomedical Research Unit, Leeds Teaching Hospitals NHS Trust, Leeds, UK

${ }^{10}$ Department of Rheumatology, Lund University Hospital, Lund, Sweden

${ }^{11}$ Stanford Prevention Research Center, Stanford University School of Medicine,

Stanford, USA

12Department of Hygiene and Epidemiology, School of Medicine, University of Ioannina, Ioannina, Greece

${ }^{13}$ Department of Medicine, Tufts University School of Medicine, Boston, USA

${ }^{14}$ Harvard School of Public Health, Boston, USA

${ }^{15}$ Renal Unit, Addenbrooke's Hospital, Cambridge, UK

${ }^{16}$ Department of Rheumatology and Clinical Immunology, University Medical Center Groningen, Groningen, The Netherlands

${ }^{17}$ Department of Rheumatology and Clinical Immunology, Justus-Liebig Universität Giessen, Bad Nauheim, Germany

${ }^{18}$ Department for Scientific Research, Bezhanijska Kosa University Medical Center,

Belgrade, Serbia

${ }^{19}$ Department of Medicine, Sapienza Università di Roma, Rome, Italy

${ }^{20}$ Department of Pediatric Immunology, University Medical Center Utrecht, Utrecht, The Netherlands

Funding EULAR.

Competing interests None.

Provenance and peer review Not commissioned; externally peer reviewed.

\section{REFERENCE}

1. Falagas ME, Manta KG, Betsi Gl, et al. Infection-related morbidity and mortality in patients with connective tissue diseases: a systematic review. Clin Rheumatol 2007;26:663-70

2. Bosch X, Guilabert $A$, Pallarés $L$, et al. Infections in systemic lupus erythematosus: a prospective and controlled study of 110 patients. Lupus 2006;15:584-9.

3. Doran MF, Crowson CS, Pond GR, et al. Frequency of infection in patients with rheumatoid arthritis compared with controls: a population-based study. Arthritis Rheum 2002;46:2287-93

4. Wolfe F, Mitchell DM, Sibley JT, et al. The mortality of rheumatoid arthritis. Arthritis Rheum 1994;37:481-94.

5. Cervera R, Khamashta MA, Font J, et al. Morbidity and mortality in systemic lupus erythematosus during a 10-year period: a comparison of early and late manifestations in a cohort of 1,000 patients. Medicine (Baltimore) 2003;82:299-308.

6. Steen VD, Medsger TA. Changes in causes of death in systemic sclerosis, 1972-2002. Ann Rheum Dis 2007:66:940-4.

7. Ruangjutipopan S, Kasitanon N, Louthrenoo W, et al. Causes of death and poor survival prognostic factors in thai patients with systemic sclerosis. J Med Assoc Thai 2002;85:1204-9.

8. Hoffman GS, Kerr GS, Leavitt RY, et al. Wegener granulomatosis: an analysis of 158 patients. Ann Intern Med 1992;116:488-98.

9. Reinhold-Keller E, Beuge N, Latza U, et al. An interdisciplinary approach to the care of patients with Wegener's granulomatosis: long-term outcome in 155 patients. Arthritis Rheum 2000;43:1021-32.

10. Marie I, Hachulla E, Chérin P, et al. Opportunistic infections in polymyositis and dermatomyositis. Arthritis Rheum 2005;53:155-65.

11. Furst DE, Breedveld FC, Kalden JR et al. Updated consensus statement on biological agents for the treatment of rheumatic diseases, 2007. Ann Rheum Dis 2007;66(Suppl 3):iii2-22.

12. Chen YF, Jobanputra P, Barton $P$, et al. A systematic review of the effectiveness of adalimumab, etanercept and infliximab for the treatment of rheumatoid arthritis in adults and an economic evaluation of their cost-effectiveness. Health Technol Assess 2006;10:iii-iv, xi-xiii, 1-229.

13. Kremer JM, Genant HK, Moreland LW, et al. Effects of abatacept in patients with methotrexate-resistant active rheumatoid arthritis: a randomized trial. Ann Intern Med 2006;144:865-76.

14. Genovese MC, Becker JC, Schiff M, et al. Abatacept for rheumatoid arthritis refractory to tumor necrosis factor alpha inhibition. N Engl J Med 2005;353:1114-23

15. Cohen SB, Moreland LW, Cush JJ, et al. A multicentre, double blind, randomised placebo controlled trial of anakinra (Kineret), a recombinant interleukin 1 receptor 
antagonist, in patients with rheumatoid arthritis treated with background methotrexate. Ann Rheum Dis 2004;63:1062-8

16. Nuki G, Bresnihan B, Bear MB, et al. Long-term safety and maintenance of clinical improvement following treatment with anakinra (recombinant human interleukin-1 receptor antagonist) in patients with rheumatoid arthritis: extension phase of a randomized, double-blind, placebo-controlled trial. Arthritis Rheum 2002;46:2838-46.

17. Keystone E, Fleischmann R, Emery P, et al. Safety and efficacy of additional courses of rituximab in patients with active rheumatoid arthritis: an open-label extension analysis. Arthritis Rheum 2007;56:3896-908.

18. Edwards JC, Szczepanski L, Szechinski J, et al. Efficacy of B-cell-targeted therapy with rituximab in patients with rheumatoid arthritis. N Engl J Med 2004;350:2572-81.

19. Emery P, Fleischmann R, Filipowicz-Sosnowska A, et al. The efficacy and safety of rituximab in patients with active rheumatoid arthritis despite methotrexate treatment results of a phase IIB randomized, double-blind, placebo-controlled, dose-ranging trial. Arthritis Rheum 2006;54:1390-400.

20. McLeod C, Bagust A, Boland A, et al. Adalimumab, etanercept and infliximab for the treatment of ankylosing spondylitis: a systematic review and economic evaluation. Health Technol Assess 2007;11:1-158, iii-iv.

21. Lequerré $\mathbf{T}$, Quartier $P$, Rosellini $D$, et al. Interleukin-1 receptor antagonist (anakinra) treatment in patients with systemic-onset juvenile idiopathic arthritis or adult onset Still disease: preliminary experience in France. Ann Rheum Dis 2008;67:302-8.

22. Pijpe J, van Imhoff GW, Spijkervet FK, et al. Rituximab treatment in patients with primary Sjögren's syndrome: an open-label phase II study. Arthritis Rheum 2005; 52:2740-50

23. Smolen JS, Beaulieu A, Rubbert-Roth A, et al. Effect of interleukin-6 receptor inhibition with tocilizumab in patients with rheumatoid arthritis (OPTION study): a double-blind, placebo-controlled, randomised trial. Lancet 2008;371:987-97.

24. Louie JS, Nies KM, Shoji KT, et al. Clinical and antibody responses after influenza immunization in systemic lupus erythematosus. Ann Intern Med 1978;88:790-2.

25. Ristow SC, Douglas RG, Jr, Condemi JJ. Influenza vaccination of patients with systemic lupus erythematosus. Ann Intern Med 1978;88:786-9.

26. Zycinska K, Romanowska M, Nowak I, et al. Antibody response to inactivated subunit influenza vaccine in patients with Wegener's granulomatosis. J Physiol Pharmacol 2007:58 Suppl 5(Pt 2):819-28.

27. King SM, Saunders EF, Petric M, et al. Response to measles, mumps and rubella vaccine in paediatric bone marrow transplant recipients. Bone Marrow Transplant 1996;17:633-6.

28. Levin MJ, Gershon AA, Weinberg A, et al. Administration of live varicella vaccine to HIV-infected children with current or past significant depression of CD4(+) T cells. J Infect Dis 2006;194:247-55.

29. Harpaz R, Ortega-Sanchez IR, Seward JF. Prevention of herpes zoster: recommendations of the Advisory Committee on Immunization Practices (ACIP). MMWR Recomm Rep 2008;57(RR-5):1-30; quiz CE2-4.

30. Denman EJ, Denman AM, Greenwood BM, et al. Failure of cytotoxic drugs to suppress immune responses of patients with rheumatoid arthritis. Ann Rheum Dis 1970;29:220-31.

31. Herron A, Dettleff $G$, Hixon B, et al. Influenza vaccination in patients with rheumatic diseases. Safety and efficacy. JAMA 1979;242:53-6.

32. Turner-Stokes L, Cambridge G, Corcoran T, et al. In vitro response to influenza immunisation by peripheral blood mononuclear cells from patients with systemic lupus erythematosus and other autoimmune diseases. Ann Rheum Dis 1988;47:532-5

33. Chalmers A, Scheifele D, Patterson C, et al. Immunization of patients with rheumatoid arthritis against influenza: a study of vaccine safety and immunogenicity. J Rheumatol 1994:21:1203-6.

34. Del Porto F, Laganà $B$, Biselli $R$, et al. Influenza vaccine administration in patients with systemic lupus erythematosus and rheumatoid arthritis. Safety and immunogenicity. Vaccine 2006;24:3217-23.

35. Fomin I, Caspi D, Levy V, et al. Vaccination against influenza in rheumatoid arthritis the effect of disease modifying drugs, including TNF alpha blockers. Ann Rheum Dis 2006;65:191-4

36. Kaine JL, Kivitz AJ, Birbara C, et al. Immune responses following administration of influenza and pneumococcal vaccines to patients with rheumatoid arthritis receiving adalimumab. J Rheumatol 2007:34:272-9.

37. Kubota T, Nii T, Nanki T, et al. Anti-tumor necrosis factor therapy does not diminish the immune response to influenza vaccine in Japanese patients with rheumatoid arthritis. Mod Rheumatol 2007;17:531-3.

38. Gelinck LB, van der Bijl AE, Beyer WE, et al. The effect of anti-tumour necrosis factor alpha treatment on the antibody response to influenza vaccination. Ann Rheum Dis 2008; 67:713-6

39. Nii T, Kubota T, Nanki T, et al. Reevaluation of antibody titers 1 year after influenza vaccination in patients with rheumatoid arthritis receiving TNF blockers. Mod Rheumatol 2009:19:216-8.

40. Elkayam 0, Bashkin A, Mandelboim M, et al. The effect of infliximab and timing of vaccination on the humoral response to influenza vaccination in patients with rheumatoid arthritis and ankylosing spondylitis. Semin Arthritis Rheum 2010:39:442-7.
41. van Assen S, Holvast A, Benne CA, et al. Humoral responses after influenza vaccination are severely reduced in patients with rheumatoid arthritis treated with rituximab. Arthritis Rheum 2010;62:75-81.

42. Elkayam 0, Paran D, Caspi D, et al. Immunogenicity and safety of pneumococcal vaccination in patients with rheumatoid arthritis or systemic lupus erythematosus. Clin Infect Dis 2002;34:147-53.

43. Elkayam $\mathbf{0}$, Caspi D, Reitblatt $\mathrm{T}$, et al. The effect of tumor necrosis factor blockade on the response to pneumococcal vaccination in patients with rheumatoid arthritis and ankylosing spondylitis. Semin Arthritis Rheum 2004;33:283-8.

44. Visvanathan S, Keenan GF, Baker DG, et al. Response to pneumococcal vaccine in patients with early rheumatoid arthritis receiving infliximab plus methotrexate or methotrexate alone. J Rheumatol 2007;34:952-7.

45. Kapetanovic MC, Saxne T, Sjöholm A, et al. Influence of methotrexate, TNF blockers and prednisolone on antibody responses to pneumococcal polysaccharide vaccine in patients with rheumatoid arthritis. Rheumatology (Oxford) 2006;45:106-11.

46. Devey ME, Bleasdale K, Isenberg DA. Antibody affinity and IgG subclass of responses to tetanus toxoid in patients with rheumatoid arthritis and systemic lupus erythematosus. Clin Exp Immunol 1987;68:562-9.

47. Mercado U, Acosta H, Avendaño L. Influenza vaccination of patients with systemic lupus erythematosus. Rev Invest Clin 2004;56:16-20.

48. Pons VG, Reinertsen JL, Steinberg AD, et al. Decreased cell-mediated cytotoxicity against virus-infected cells in systemic lupus erythematosus. J Med Virol 1979;4:15-23.

49. Williams GW, Steinberg AD, Reinertsen JL, et al. Influenza immunization in systemic lupus eruthematosus. A double-blind trial. Ann Intern Med 1978;88:729-34.

50. Brodman R, Gilfillan $R$, Glass $D$, et al. Influenzal vaccine response in systemic lupus erythematosus. Ann Intern Med 1978;88:735-40.

51. Lipnick RN, Karsh J, Stahl NI, et al. Pneumococcal immunization in patients with systemic lupus erythematosus treated with immunosuppressives. J Rheumatol 1985; 12:1118-21.

52. Croft SM, Schiffman G, Snyder E, et al. Specific antibody response after in vivo antigenic stimulation in systemic lupus erythematosus. J Rheumatol 1984;11:141-6.

53. Tarián P, Sipka S, Maródi L, et al. No short-term immunological effects of Pneumococcus vaccination in patients with systemic lupus erythematosus. Scand J Rheumatol 2002;31:211-5.

54. Jarrett MP, Schiffman G, Barland P, et al. Impaired response to pneumococcal vaccine in systemic lupus erythematosus. Arthritis Rheum 1980;23:1287-93.

55. Kuruma KA, Borba EF, Lopes MH, et al. Safety and efficacy of hepatitis B vaccine in systemic lupus erythematosus. Lupus 2007;16:350-4.

56. Elkayam 0, Yaron M, Caspi D. Safety and efficacy of vaccination against hepatitis B in patients with rheumatoid arthritis. Ann Rheum Dis 2002;61:623-5.

57. Erkek $\mathbf{E}$, Ayaslioglu $E$, Erkek $A B$, et al. Response to vaccination against hepatitis $B$ in patients with Behcet's disease. J Gastroenterol Hepatol 2005;20:1508-11.

58. Kashef S, Ghazizadeh F, Derakhshan A, et al. Antigen-specific antibody response in juvenile-onset SLE patients following routine immunization with tetanus toxoid. Iran J Immunol 2008:5:181-4.

59. Abe T, Homma M. Immunological reactivity in patients with systemic lupus erythematosus. Humoral antibody and cellular immune responses. Acta Rheumatol Scand 1971;17:35-46.

60. Battafarano DF, Battafarano NJ, Larsen L, et al. Antigen-specific antibody responses in lupus patients following immunization. Arthritis Rheum 1998;41:1828-34.

61. Nies K, Boyer R, Stevens R, et al. Anti-tetanus toxoid antibody synthesis after booster immunization in systemic lupus erythematosus. Comparison of the in vitro and in vivo responses. Arthritis Rheum 1980;23:1343-50.

62. Mease PJ, Ritchlin CT, Martin RW, et al. Pneumococcal vaccine response in psoriatic arthritis patients during treatment with etanercept. J Rheumatol 2004;31:1356-61.

63. Holvast A, Huckriede A, Wilschut J, et al. Safety and efficacy of influenza vaccination in systemic lupus erythematosus patients with quiescent disease. Ann Rheum Dis 2006;65:913-8.

64. Franco Salinas G, de Rycke L, Cantaert T, et al. TNF blockade impairs T-cell dependant antibody response. Ann Rheum Dis 2009;68(Suppl 3):238.

65. Wiesik-Szewczyk E, Romanowska M, Mielnik P, et al. Anti-influenza vaccination in systemic lupus erythematosus patients: an analysis of specific humoral response and vaccination safety. Clin Rheumatol 2010;29:605-13.

66. Wiesik-Szewczyk E, Romanowska M, Mielnik P, et al. Predictors of antigenspecific response for influenza vaccination on lupus patients. Ann Rheum Dis 2009;68(Suppl 3):263.

67. Kapetanovic MC, Saxne T, Nilsson JA, et al. Influenza vaccination as mode for testing immune modulation induced by anti-TNF and methotrexate therapy in rheumatoid arthritis patients. Rheumatology (Oxford) 2007:46:608-11.

68. Abu-Shakra M, Press J, Varsano N, et al. Specific antibody response after influenza immunization in systemic lupus erythematosus. J Rheumatol 2002;29:2555-7.

69. Gelinck LB, van der Bijl AE, Visser LG, et al. Synergistic immunosuppressive effect of anti-TNF combined with methotrexate on antibody responses to the 23 valent pneumococcal polysaccharide vaccine. Vaccine 2008;26:3528-33.

70. Oren S, Mandelboim M, Braun-Moscovici Y, et al. Vaccination against influenza in patients with rheumatoid arthritis: the effect of rituximab on the humoral response. Ann Rheum Dis 2008:67:937-41. 
71. Bingham CO 3rd, Looney RJ, Deodhar A, et al. Immunization responses in rheumatoid arthritis patients treated with rituximab: results from a controlled clinical trial. Arthritis Rheum 2010:62:64-74.

72. Little MA, Nightingale P, Verburgh CA, et al. Early mortality in systemic vasculitis: relative contribution of adverse events and active vasculitis. Ann Rheum Dis 2010;69:1036-43

73. Nichol KL, Wuorenma J, von Sternberg T. Benefits of influenza vaccination for low-, intermediate-, and high-risk senior citizens. Arch Intern Med 1998;158:1769-76.

74. Hak E, Nordin J, Wei F, et al. Influence of high-risk medical conditions on the effectiveness of influenza vaccination among elderly members of 3 large managed care organizations. Clin Infect Dis 2002;35:370-7.

75. Holvast A, Stegeman CA, Benne CA, et al. Wegener's granulomatosis patients show an adequate antibody response to influenza vaccination. Ann Rheum Dis 2009;68:873-8.

76. Setti M, Fenoglio D, Ansaldi F, et al. Flu vaccination with a virosomal vaccine does not affect clinical course and immunological parameters in scleroderma patients. Vaccine 2009;27:3367-72

77. Stojanovich L. Influenza vaccination of patients with systemic lupus erythematosus (SLE) and rheumatoid arthritis (RA). Clin Dev Immunol 2006;13:373-5.

78. Gelinck LB, Teng YK, Rimmelzwaan GF, et al. Poor serological responses upon influenza vaccination in patients with rheumatoid arthritis treated with rituximab. Ann Rheum Dis 2007;66:1402-3

79. Pellegrini M, Nicolay U, Lindert K, et al. MF59-adjuvanted versus non-adjuvanted influenza vaccines: integrated analysis from a large safety database. Vaccine 2009;27:6959-65.

80. McDonald E, Jarrett MP, Schiffman G, et al. Persistence of pneumococcal antibodies after immunization in patients with systemic lupus erythematosus. J Rheumatol 1984;11:306-8.

81. Favalli EG, Desiati F, Atzeni F, et al. Serious infections during anti-TNFalpha treatment in rheumatoid arthritis patients. Autoimmun Rev 2009;8:266-73.

82. Strangfeld A, Listing J, Herzer P, et al. Risk of herpes zoster in patients with rheumatoid arthritis treated with anti-TNF-alpha agents. JAMA 2009;301:737-44.

83. McDonald JR, Zeringue AL, Caplan L, et al. Herpes zoster risk factors in a national cohort of veterans with rheumatoid arthritis. Clin Infect Dis 2009;48:1364-71.

84. Smitten AL, Choi HK, Hochberg MC, et al. The risk of herpes zoster in patients with rheumatoid arthritis in the United States and the United Kingdom. Arthritis Rheum 2007; 57:1431-8.

85. Wolfe F, Michaud K, Chakravarty EF. Rates and predictors of herpes zoster in patients with rheumatoid arthritis and non-inflammatory musculoskeletal disorders. Rheumatology (Oxford) 2006;45:1370-5.

86. Antonelli MA, Moreland LW, Brick JE. Herpes zoster in patients with rheumatoid arthritis treated with weekly, low-dose methotrexate. Am J Med 1991;90:295-8.

87. Speerstra F, Boerbooms AM, van de Putte LB, et al. Side-effects of azathioprine treatment in rheumatoid arthritis: analysis of 10 years of experience. Ann Rheum Dis 1982;41(Suppl 1):37-9.

88. Ginzler $\mathbf{E}$, Diamond $\mathrm{H}$, Kaplan D, et al. Computer analysis of factors influencing frequency of infection in systemic lupus erythematosus. Arthritis Rheum 1978;21:37-44.

89. Kang TY, Lee HS, Kim TH, et al. Clinical and genetic risk factors of herpes zoster in patients with systemic lupus erythematosus. Rheumatol Int 2005;25:97-102.

90. Manzi S, Kuller LH, Kutzer J, et al. Herpes zoster in systemic lupus erythematosus. $J$ Rheumatol 1995;22:1254-8.

91. Kahl LE. Herpes zoster infections in systemic lupus erythematosus: risk factors and outcome. J Rheumatol 1994;21:84-6.

92. Nagasawa K, Yamauchi Y, Tada Y, et al. High incidence of herpes zoster in patients with systemic lupus erythematosus: an immunological analysis. Ann Rheum Dis 1990;49:630-3.

93. Wang F, Chua CT, Bosco J. Herpes zoster in patients with systemic lupus erythematosus. Singapore Med J 1983;24:218-20.

94. Pope JE, Krizova A, Ouimet JM, et al. Close association of herpes zoster reactivation and systemic lupus erythematosus (SLE) diagnosis: case-control study of patients with SLE or noninflammatory nusculoskeletal disorders. J Rheumatol 2004;31:274-9.

95. Nagaoka S, Tani K, Ishigatsubo Y, et al. Herpes zoster in patients with polymyositis and dermatomyositis. Kansenshogaku Zasshi 1990;64:1394-9.

96. Wung PK, Holbrook JT, Hoffman GS, et al. Herpes zoster in immunocompromised patients: incidence, timing, and risk factors. Am J Med 2005;118:1416.

97. Gordon KB, Gottlieb AB, Gianinni EH, et al. Clinical trial safety data of events of interest in patients receiving etanercept (ENBREL $($ ) ) across approved indications. ACR Annual Meeting 2007, abstract 960

98. Weinblatt ME, Genovese MC, Moreland LW, et al. Efficacy and safety of up to 10

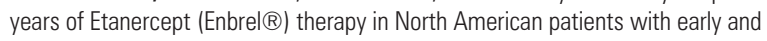
long-standing rheumatoid arthritis ACR Annual Meeting 2007, abstract 957.

99. Perez-Zafrilla B, Garcia Doval I, Carmona L. Rates of herpes zoster in patients with rheumatoid arthritis and treatment with TNF antagonists. Incidence rate in Biobadaser cohort in comparison with Emecar cohort. Ann Rheum Dis2008;67(Suppl 2):327.
100. Salliot C, Bombardier C, van der Heide D. Long term safety of methotrexate in rheumatoid arthritis; a systematic literature review. Ann Rheum Dis 2008;67(Suppl 2):204

101. Merrill JT, Neuwelt CM, Wallace DJ, et al. Rituximab in extra-renal SLE patients showed no significant difference compared to placebo at 52 weeks in the randomized, double-blind phase II/III study EXPORER. Ann Rheum Dis 2009;68(Suppl 3):249.

102. Oxman MN, Levin MJ, Johnson GR, et al. A vaccine to prevent herpes zoster and postherpetic neuralgia in older adults. N Engl J Med 2005;352:2271-84.

103. Tam LS, Chan AY, Chan PK, et al. Increased prevalence of squamous intraepithelial lesions in systemic lupus erythematosus: association with human papillomavirus infection. Arthritis Rheum 2004;50:3619-25.

104. Nath R, Mant C, Luxton J, et al. High risk of human papillomavirus type 16 infections and of development of cervical squamous intraepithelial lesions in systemic lupus erythematosus patients. Arthritis Rheum 2007;57:619-25.

105. Lee $\mathbf{Y}$, Choe J, Kim J, et al. Prevalence and risk factors for human papillomavirus infection and cervical cytological abnormalities in Korean patients with systemic lupus erythematosus. ACR Annual Meeting 2007: abstract 1105

106. Tam L, Chan PS, Ho S, et al. Natural history of cervical human papillomavirus infection among women with systemic lupus erythematosus. Ann Rheum Dis 2009;68(Suppl 3):128

107. Slade BA, Leidel L, Vellozzi C, et al. Postlicensure safety surveillance for quadrivalent human papillomavirus recombinant vaccine. JAMA 2009:302:750-7.

108. Kyaw MH, Holmes EM, Toolis F, et al. Evaluation of severe infection and survival after splenectomy. Am J Med 2006;119:276.e1-7.

109. Brigden ML, Pattullo AL. Prevention and management of overwhelming postsplenectomy infection-an update. Crit Care Med 1999;27:836-42.

110. Lynch AM, Kapila R. Overwhelming postsplenectomy infection. Infect Dis Clin North Am 1996;10:693-707.

111. Styrt B. Infection associated with asplenia: risks, mechanisms, and prevention. Am J Med 1990;88(5N):33-42N

112. Green JB, Shackford SR, Sise MJ, et al. Late septic complications in adults following splenectomy for trauma: a prospective analysis in 144 patients. J Trauma 1986:26:999-1004

113. Davies JM, Barnes R, Milligan D. Update of guidelines for the prevention and treatment of infection in patients with an absent or dysfunctional spleen. Clin Med 2002;2:440-3.

114. Watson DA. Pretravel health advice for asplenic individuals. J Travel Med 2003;10:117-21

115. Brassard $\mathbf{P}$, Lowe AM, Bernatsky S, et al. Rheumatoid arthritis, its treatments, and the risk of tuberculosis in Quebec, Canada. Arthritis Rheum 2009:61:300-4.

116. Askling J, Fored CM, Brandt L, et al. Risk and case characteristics of tuberculosis in rheumatoid arthritis associated with tumor necrosis factor antagonists in Sweden. Arthritis Rheum 2005;52:1986-92.

117. Brassard P, Kezouh A, Suissa S. Antirheumatic drugs and the risk of tuberculosis. Clin Infect Dis 2006; 43:717-22.

118. Gómez-Reino JJ, Carmona L, Valverde VR, et al. Treatment of rheumatoid arthritis with tumor necrosis factor inhibitors may predispose to significant increase in tuberculosis risk: a multicenter active-surveillance report. Arthritis Rheum 2003:48:2122-7.

119. Seong SS, Choi CB, Woo JH, et al. Incidence of tuberculosis in Korean patients with rheumatoid arthritis (RA): effects of RA itself and of tumor necrosis factor blockers. J Rheumatol 2007;34:706-11.

120. Bernatsky S, Bombardier C, Bhamani A, et al. Tuberculosis in a population-based cohort of seniors with rheumatoid arthritis. Ann Rheum Dis 2009;68(Suppl 3):568.

121. Askling J. Risk for tuberculosis following treatment of rheumatoid arthritis with anti-TNF therapy - the Swedish experience 1998-2008. Ann Rheum Dis 2009;68(Suppl 3):422

122. Baronnet L, Kahn V, Lacoin C, et al. Tuberculosis incidence in rheumatoid arthritis affected patients. Ann Rheum Dis 2008;67(Suppl 2):544.

123. Mines D, Gu Y, Liu Q, et al. Risk of active tuberculosis (TB) among biologic-naive patients: retrospective cohort study in a US claims database. Ann Rheum Dis 2008:67(Suppl 2):91.

124. Tubach F, Salmon D, Ravaud P, et al. The risk of tuberculosis with anti-TNF is higher with monoclonal antibodies than with the soluble receptor. Results of the French 3-year prospective RATIO observatory. Ann Rheum Dis 2008;67(Suppl 2):52.

125. Dixon WG, Hyrich KL, Watson KD, et al. Specific risk of tuberculosis in patients with rheumatoid arthritis treated with anti-TNF therapy: results from the BSR Biologic Register (BSRBR). Ann Rheum Dis 2008;67(Suppl 2):178.

126. Dixon WG, Hyrich KL, Watson KD, et al. Drug-specific risk of tuberculosis in patients with rheumatoid arthritis treated with anti-TNF therapy: results from the BSRBR. ACR Annual Meeting 2008: abstract 1263.

127. Kim HA, Yoo CD, Baek HJ, et al. Mycobacterium tuberculosis infection in a corticosteroid-treated rheumatic disease patient population. Clin Exp Rheumatol 1998;16:9-13.

128. Sayarlioglu M, Inanc M, Kamali S, et al. Tuberculosis in Turkish patients with systemic lupus erythematosus: increased frequency of extrapulmonary localization. Lupus 2004;13:274-8. 
129. Tam LS, Li EK, Wong SM, et al. Risk factors and clinical features for tuberculosis among patients with systemic lupus erythematosus in Hong Kong. Scand J Rheumatol 2002;31:296-300.

130. Marti F, Steffen R, Mutsch M. Influenza vaccine: a travelers' vaccine? Expert Rev Vaccines 2008:7:679-87.

131. Mutsch M, Tavernini M, Marx A, et al. Influenza virus infection in travelers to tropical and subtropical countries. Clin Infect Dis 2005;40:1282-7.

132. Karpelowsky JS, Alexander AG, Peek SD, et al. Surgical complications of bacille Calmette-Guérin (BCG) infection in HIV-infected children: time for a change in policy. S Afr Med J 2008;98:801-4.
133. Hesseling AC, Johnson LF, Jaspan $\mathrm{H}$, et al. Disseminated bacille Calmette-Guérin disease in HIV-infected South African infants. Bull World Health Organ 2009;87:505-11.

134. Kawashima H, Hasegawa D, Nakamura M, et al. Hazards of early BCG vaccination: BCGitis in a patient with chronic granulomatous disease. Pediatr Int 2007;49:418-9.

135. Jefferson T, Di Pietrantonj C, Rivetti $A$, et al. Vaccines for preventing influenza in healthy adults. Cochrane Database Syst Rev 2010;7:CD001269.

136. Jefferson T, Di Pietrantonj $C$, Al-Ansary LA, et al. Vaccines for preventing influenza in the elderly. Cochrane Database Syst Rev 2010;2:CD004876.

137. Huss A, Scott P, Stuck AE, et al. Efficacy of pneumococcal vaccination in adults: a meta-analysis. CMAJ 2009;180:48-58. 